\section{Organic vs. psychogenic tics}

Dear Editor,

We would like to comment on Mejia and Jankovic's paper: "Secondary Tics and Tourettism". First, it is remarkable that secondary tics were twice as prevalent in males (65.1\%) as in females (34.8\%). The higher prevalence of Tourette's syndrome (TS) in males is well-known, and this study could point to a greater susceptibility of males to develop tics be the cause TS or not.

Second, some points remained unclear, such as the criteria for diagnosing psychogenic tics. As the rate of $10.3 \%$ is quite high, the criteria used should have been specified. Others have documented psychogenic movement disorders (PMD) prevalence rates in about $3.3 \%$ of the cases, but tics were rarely found in their samples. ${ }^{1}$

The cited reference ${ }^{2}$ provides a diagnostic guideline for PMD such as dystonia, tremor, paroxistic dyskinesia, parkinsonism, gait disorders, hemifacial spasm, spasmodic dysphonia, and myoclonia, but has not included psychogenic tics.

Fahn and Williams classified patients in four categories (documented, clinically established, probable and possible) based on the level of certainty of having psychogenic dystonia. This classification is often used for other movement disorders. They define documented PMD as involuntary movements which are persistently relieved by psychotherapy, suggestion, placebo, or the patient is witnessed as being free from the involuntary movements when supposedly unobserved; and clinically established PMD are movements which are inconsistent or incongruent with classic descriptions of the acknowledged movement disorder, associated with other psychogenic signs on neurological examination, multiple somatizations, or obvious psychiatric disturbance. The probable and possible categories have less clinical evidence being often excluded from most studies. ${ }^{3}$

Thomas and Jankovic ${ }^{2}$ describe indicators of presence of PMD including abrupt onset with disability soon or immediately after onset; response to placebo or suggestion, selective disability, dramatic resolution, increase with attention and cessation with distraction. Those criteria may not differentiate organic from psychogenic tics. Tic disorders usually have a waxing and waning course, may begin abruptly and with maximal severity. Tics may also be under some voluntary control, thus, temporary suppression of symptoms may often occur. Their intensity may also vary with attention (usually decreasing with distraction), a differential feature of psychogenic tremor that may not be valid for tics. ${ }^{2}$

Organic movement disorders are more frequently misdiagnosed as psychogenic than the opposite, ${ }^{4}$ and their coexistence is very common. ${ }^{1}$ The current diagnostic criteria used for PMD are not definitive and should be considered rather as a useful guide for clinical investigation. Conversive disorder should be considered after the exclusion of neurological diagnoses.

The high frequency of psychogenic tics in this sample indicates the need of well-defined criteria to characterize psychogenic tics. This dichotomy of organic versus psychogenic tics remounts to Charcot's era, when Gilles de La Tourette's syndrome or maladie des tics at that time, was considered a heredo-degenerative disease, contrarily to hysteria and chorea (the supposed psychogenic tics). However, as "organic" tics may begin or aggravate due to stressor events, we emphasize the need of careful assessment and development of rigid criteria for psychogenic tic disorder diagnosis.

Aline Sampaio, Ana G Hounie
Projeto Transtorno do Espectro Obssessivo-Compulsivo
(PROTOC) do Instituto de Psiquiatria do Hospital das
Clínicas da Faculdade de Medicina da Universidade de São
Paulo (FMUSP)
Financing: None
Conflict of interests: None

\section{References}

1. Factor SA, Podskalny GD, Molho ES. Psychogenic movement disorders: frequency, clinical profile, and characteristics. J Neurol Neurosurg Psychiatry. 1995;59(4):406-12.

2. Thomas M, Jankovic J. Psychogenic movement disorders: diagnosis and management. CNS Drugs. 2004;18(7):437-52.

3. Fahn S, Williams DT. Psychogenic dystonia. Adv Neurol. 1998;50:431-55.

4. Marjama J, Troster AL, Koller WC. Psychogenic movement disorders. Neurol Clin. 1995;13(2):283-97.

\section{On Secondary Tics and Tourettism}

\section{Dear Editor,}

We kindly thank Drs. Hounie and Sampaio for their interest in our recent paper on "Secondary tics and tourettism". ${ }^{1}$ As they mentioned, our sample of 155 patients with tics and coexistent disorders included 101 (65.1\%) male and 54 female (34.8\%) patients. Although a higher prevalence of Tourette syndrome (TS) in males has been well recognized, ${ }^{2}$ we consider the higher proportion of male patients in our population of patients with secondary tics coincidental and do not believe that our study provides sufficient data to point to a greater susceptibility of males to develop secondary tics. Nonetheless, we believe that the study of risk factors associated with the development of secondary tics, including gender, may play an important role in understanding the physiopathology of tics and TS.

We would also like to clarify that the 16 (10.3\%) patients found to develop psychogenic tics in our series of 155 patients were diagnosed using previously published criteria. ${ }^{3}$ In all our 